\title{
Perceptive approaches to the morphological characterization of the urban contour: The case of the peri-urban landscape of Madrid
}

\author{
J. Rodríguez Romero, Carlota Sáenz de Tejada Granados, \\ Rocío Santo-Tomás Muro \\ Departamento de Arquitectura y Diseño. Universidad CEU San Pablo. Madrid. Spain \\ E-mail: rodrom@ceu.es, carlota.saenztejada@ceu.es, rocio.santotomasmuro@beca.ceu.es
}

\begin{abstract}
A growing city adapts and transforms the pre-existing topography, and with its urban fabric defines an ever-changing contour throughout history; this contour is not a clear line, but rather a fringe, where city and countryside meet and create occupancy systems that are crucial to comprehend the evolution of the urban form. We can consider this fringe as 'proximity' landscapes: landscapes that are perceived when the city is either a destination or a point of departure. The vision from afar, or when progressively approaching the city, provides both locals and tourists with certain landscape and architectural aspects that should be studied, preserved and valued for their ability to generate meaningful spaces. In this communication, we study the surrounding landscapes of Madrid by means of a Landscape Character Assessment, within the framework of the project 'Proximity landscapes of the city of Madrid. From the 19thC to the present' currently in process. Combining graphic analysis of historical cartography at a metropolitan scale with perceptive analysis techniques, special attention is drawn to certain axes and significant lookouts of the city, mapping them and evaluating their visual basins. This characterization leads to distinguishing three main landscape types surrounding Madrid, according to physical, natural and anthropogenic structures: one predominantly natural, one mainly industrial and service-related, and a third one with special historical relevance.
\end{abstract}

Keywords: Perceptive analysis, proximity landscape, landscape character, urban form, Madrid.

\section{Introduction}

Throughout history, the contour of the city has been an ever-changing element. The fringe where country and city converge varies especially, with the creation of occupancy systems that are crucial to interpret the evolution of the urban form. We can consider this peri-urban fringe as 'proximity' landscapes: landscapes that are perceived when the city is either a destination or a point of departure. The vision from afar, or when progressively approaching the city, provides both locals and tourists with certain landscape and architectural aspects that should be studied, preserved and valued for their ability to generate meaningful spaces.

A new framework for landscape valorization has raised in recent years, revolving around the European Landscape Convention (Council of Europe, 2000) and stimulating the creation of landscape inventories to study, assess and monitor the driving forces of landscape change (Antrop, 2005). A growing sensibility towards landscape protection, valuing concepts such as environment and sense of place, gives way to a change of paradigm that can aid in the creation of a new form of urbanism; one where landscape, considered to have a direct impact on the quality of life of those who experience 
it, becomes the driving tool for its design (Zárate, 2011).

The city of Madrid, due to its location, morphological characteristics, history and large green and forested areas, has great cultural, touristic and environmental interest. It is a paradigmatic case of study not only in Spain, as it is an urban growth model, but also as one of the main European capitals, with similar characteristics to Berlin, London, Vienna or Paris. Projects such as MAD-RE Plan (Sustainable Urban Development Area, 2016) and Madrid CENTRO Project (Urban Planning and Housing Area, 2010) are attempts to change the model of urban development, with an integral approach that includes urbanism, mobility, public space and social and environmental challenges cooperatively.

We take Madrid's City Council 'Plan for the Quality of Urban Landscape' (Urban Planning and Housing Area, 2009) and The Environmental Study of the Autonomous Community of Madrid (Environment and Territorial Planning Department, 2009) as the starting point for our research. The first tackles the study of the urban landscape within the city-
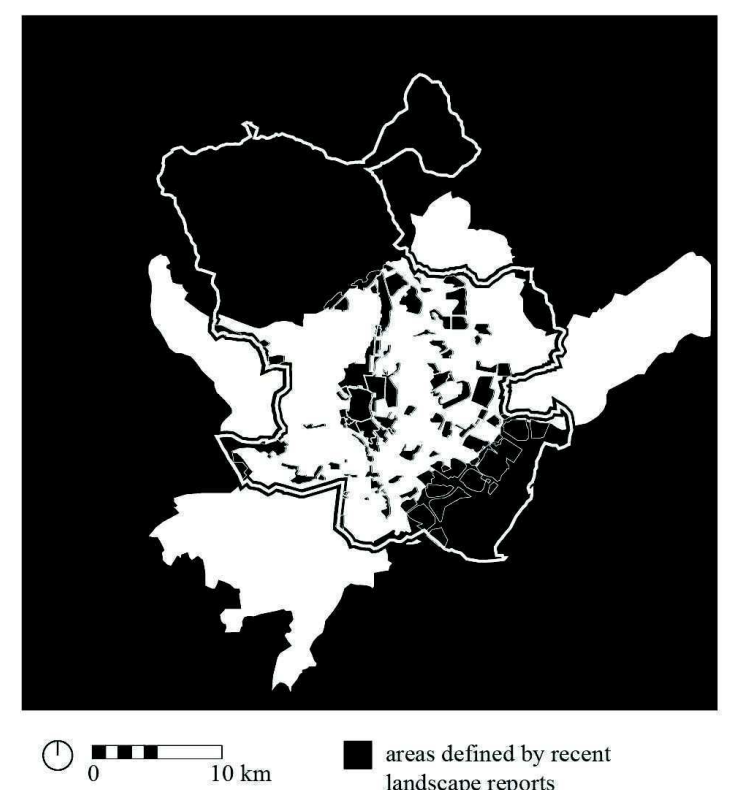

areas defined by recent landscape reports areas not yet covered by recent landscape reports

a)

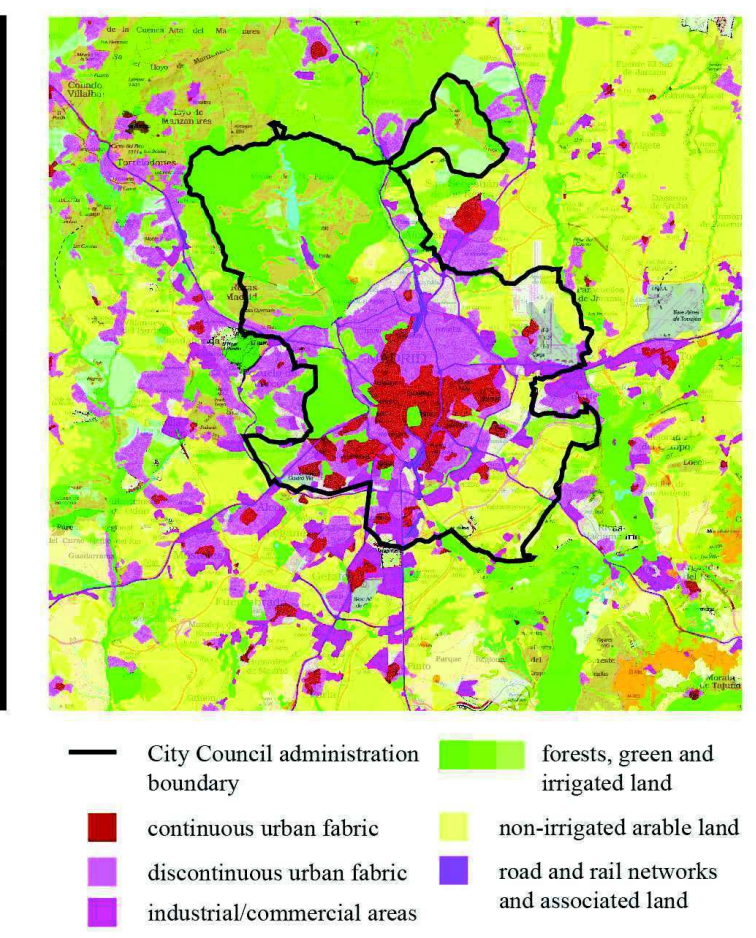

centre limits, defining units according mainly to building typology and period of construction, while the second focuses upon the natural landscape of the autonomous community and therefore leaves out the entire urban mesh of the city-centre and its surroundings [Fig. 1a)]. Both reports, of very different scope and scale, fail to address the transitional fringe between city and countryside, where there is not an existing spatial gap, but rather a clash between administration boundaries and land uses [Fig. 1b)]. It is this peri-urban fringe what becomes the focus of our research; particularly relevant areas where a deeper understanding of how urban and natural landscape influence each other can be made operational in future strategies for protection, management and development (Palang et al. 2011).

The dynamic nature of landscape calls for an integrated approach to its study, based upon holism, perception and evolution (Antrop, 2000). Characterization serves as a method to comprehend this evolution of the urban form and contour of a city, combining analytical research with perceptive approaches. We study the surrounding landscapes of Madrid by means

b)

Figure 1.

Natural landscape structures. 

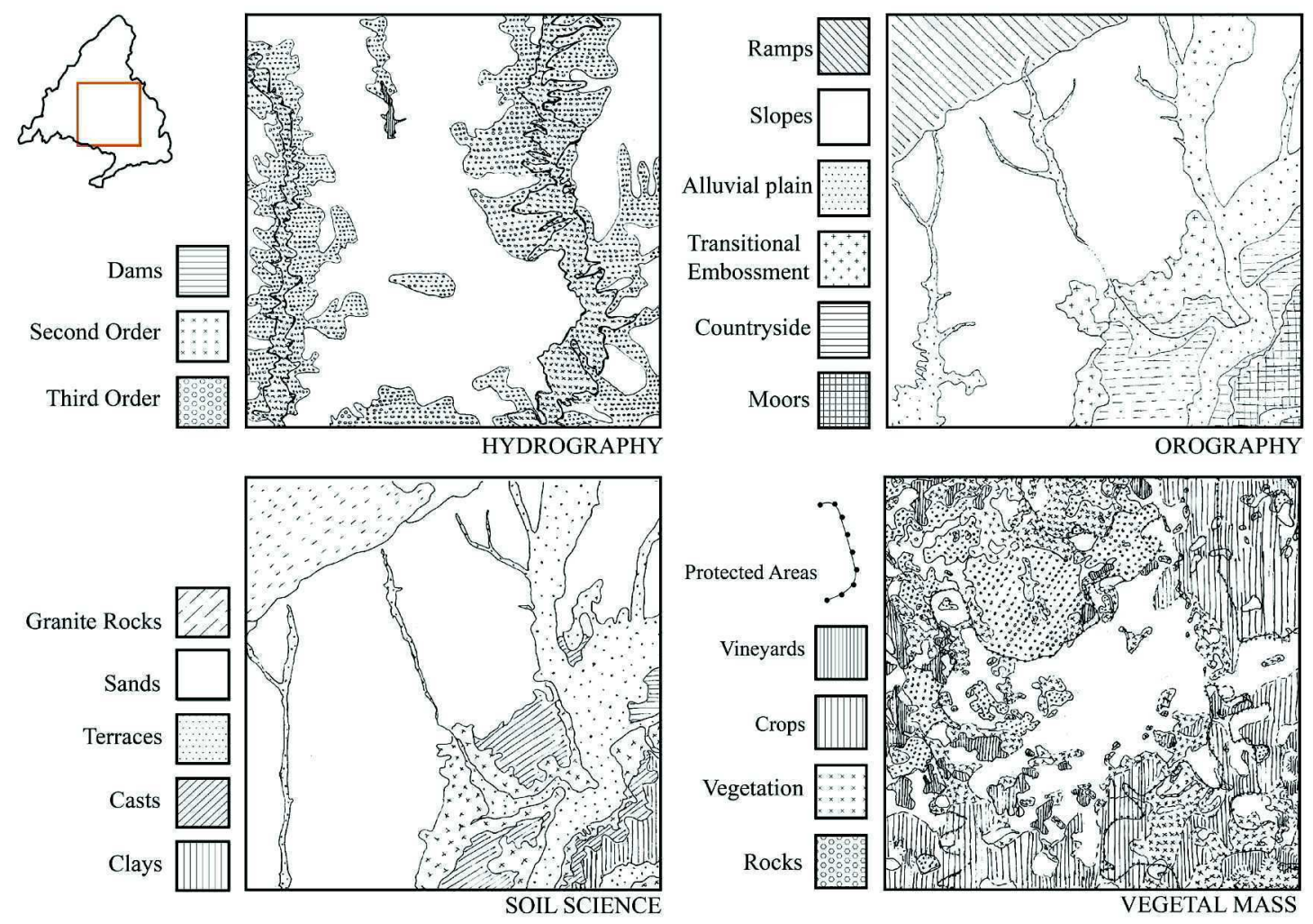

Figure 2.

Anthropogenic landscape structures.

of a Landscape Character Assessment that allows us to understand their configuration and history, in order to guide and inform in decisionmaking processes towards a more integrated urbanism. The patterns of the distinctive key elements allow for identification of variations and similarities that create sense of place and the unique character of an area. Following on from work in the 1980s, the Countryside Commission of the United Kingdom, among others, developed the technique of landscape assessment, and in 1993 Landscape Assessment Guidance was published. From its outset, in the early 1990s, the "Countryside Character Programme" was designed "to be a framework for helping to incorporate the rich heritage of landscape diversity into present day decisions, not as a process that seeks to prevent activities." (Tudor, 2014).

Overlapping thematic layers at a metropolitan scale, we distinguish between natural and anthropogenic landscape structures. The main factors affecting the first type of landscape structures are terrain (topography), soil, hydrography and vegetation [Fig. 2], allowing the delineation of big morph-structural units that can be adopted as a first approximation of perception units (Gómez, 2012). The anthropogenic structures are the changes specific to human action throughout time (historical evolution) and the various kinds of land use. The configuration amongst them is what generates a certain character of the city, especially significant in urban and peri-urban areas.

One of the main aims of this research is to corroborate the importance of landscape characterization as a tool for analysis, diagnosis and design in current and future interventions, while considering the history of those landscapes prone to change. As Madrid is currently going through several processes of urban renewal, with urbanization plans being rethought, the need for new means to support design decisions has become an ongoing reality. This method's main applicability is to provide a landscape context, guide in evidencebased policy-making, help target resources and identify opportunities for local action. 


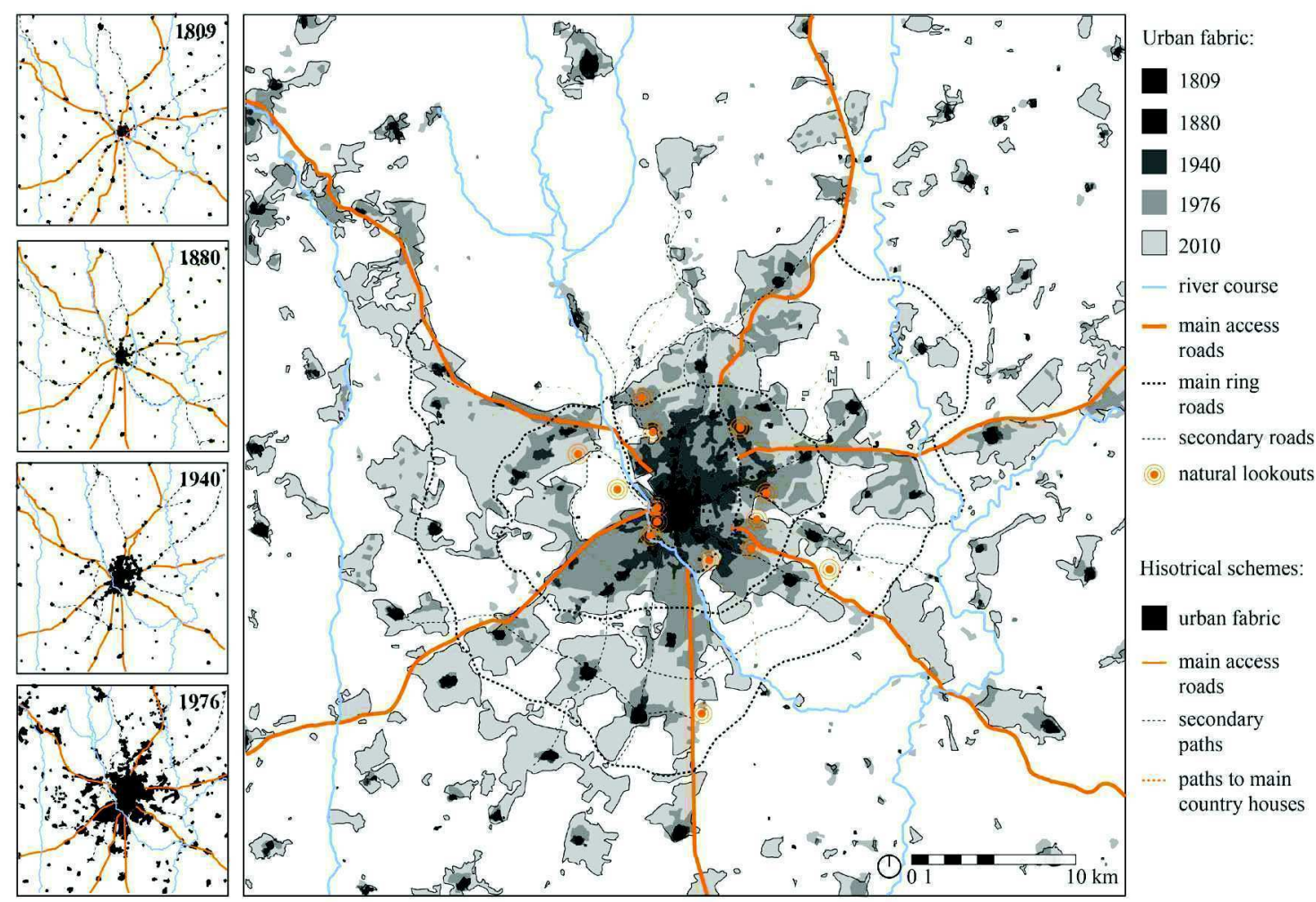

Figure 3.

Historical review of urban morphology, lookouts and main roads.

\section{Methodology}

Landscape occurs at all scales, as can the Landscape Character Assessment be undertaken. An approach to understanding how landscape is perceived by people entails constant collaboration between desk and field work, most of which has been focused upon the local scale, starting from particular areas and case studies in order to understand the metropolitan scale that enables the identification of landscape types in the outskirts of Madrid by the means of inductive aggregation, reaching general results from particular premises.

At a metropolitan scale, a historical cartography analysis of the city is developed, putting special attention to the above mentioned 'proximity' landscapes: those perceived when the city is either a destination or a point of departure. The historical plans used as support for this graphical analysis are 1809, 1880, 1940, 1976 and 2010, all of them retrieved from "Planea" database (Autonomous Community of Madrid, 2017), showing relevant stages of growth and transformation of the city [Fig.3]. Stemming from the perceptive components detected in the Landscape Diagnosis Plan of Madrid City Council's 'Plan for de Quality of Urban Landscape' (Urban Planning and Housing Area, 2009), natural lookouts and main access roads are highlighted in this analysis and considered to play a decisive role in the perception of the city and its surroundings throughout time. This cartography has been developed from a metropolitan scale (1:750000) to an urban scale (1:50000).

The perceptive approach is then carried out at a local scale, focusing on the natural lookouts and main access roads to extract perceptive data and select relevant views. Amid these framed views, we discriminate the different characters of the city from the specific sites. Analytical drawings based on these selected views introduce additional information and dimensions beyond the visual frame, focusing on the city-countryside dialogue.

For the lookouts, a 3D digital model of the area of study is generated using data form the 
National Geographic Institute (NGI, 2017), where the named lookouts are located. By means of GIS, a $360^{\circ}$ horizontal scanning of a $40 \mathrm{~km}$ radius from the height of $1.70 \mathrm{~m}$ is carried out from those points to determine their visual basins. The field work is carried out to contrast the data generated in the previous steps, comparing panoramas with the visual basins, for at this stage certain urban elements (buildings, vegetation...) affect the range of the current views.

We cover the main roads accessing the city centre, starting from the $\mathrm{m} 50$, the farthest proximity level, taking pictures along the path every 100 meters, at a speed of $100 \mathrm{~km} / \mathrm{h}$, with a frame rate of 3.6 seconds. The variations on the topography and the urban elements (billboards, banners, vegetation...) allow the identification of regions where the elevation of the city is perceptible, correlated with cross-sections that display the slopes during the route and $40 \mathrm{~km}-$ radius visual basins of particular points.

Observation and analysis applied to the Characterization of Madrid's peri-urban landscape.
The steep cut of the River Manzanares generates a stark contrast between the greenery below (provided by El Pardo Mount, Casa de Campo, Campo del Moro, Florida Avenue and the riversides) and the ensemble of sturdy architectural landmarks above (the Royal Palace and the dome of San Francisco el Grande Basilica, among others). This landscape backdrop is known as the 'cornice' of Madrid; the iconic image of the city, perceived when approached from the west, and which has been represented from the right riverbank by uncountable artists. "Las Vistillas" has been portrayed by painters and photographers and has remain a city-country lookout ever since, where the fringe between them has changed throughout time. San Isidro, another lookout that has strongly evolved over time, is the heart of the popular festivities of "La Paloma", and has been depicted by Spanish well-known painter Francisco de Goya, among others (Pinto, 1995).
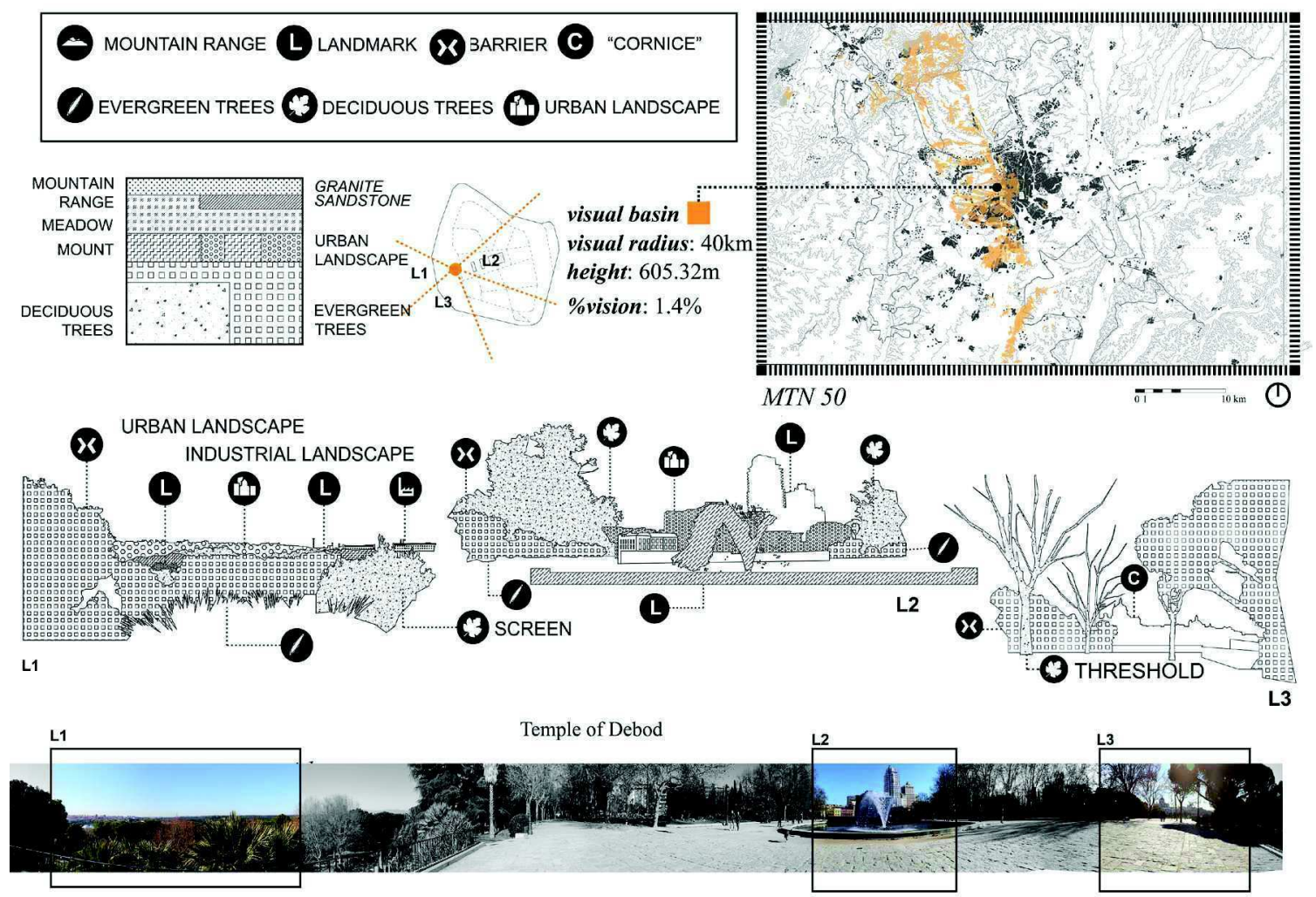

Figure 4.

Data sheet of the Temple of Debod Lookout. $360^{\circ}$ panoramas, visual basins and analytical drawings from the lookout. 
Lookouts as witnesses:

Lookouts can be considered silent witnesses of the evolution of the city (Rodríguez, Sáenz de Tejada, 2016). Therefore, a selection of natural promontories is made, according to location, topographical characteristics and historical presence. These geographical points of high altitude from which one can appreciate the city contour are accessible and public. The character of the place will depend on the natural and anthropogenic structures, the urban elements of the surroundings as well as the varying environmental conditions, such as climate, sound or smell that varies over time according to the time of the day or the season. As a case study, we take the "Temple of Debod" lookout [Fig. 4], a park on the west entrance of the city. The visual basin shows a predominance of views to the west, being able to see the fringe that exists between country and the city, whereas if we look to the East we only distinguish what is at close distance. The landscape is a combination of meadow and mount, where we can recognize the environmental elements of Casa de Campo like the pinewood that surrounds it. The $360^{\circ}$ panorama is taken from the West axis of the Egyptian temple located in the centre of the park, situated at 605.32 meters of altitude, and the different elements like the near vegetation or the street furniture act as barrier or landmark, revealing at times iconic views of the city.

As a result of the panoramas and the visual basin, we differentiate three relevant views: one looking towards the countryside, one towards the city and one framing the city's 'cornice', highlighting the different layers in landscape that can lead to a characterization. In the first frame, there is a predominance of the urban and industrial landscape of Carabanchel, a south district of the city, dominated by the towers of the factories nearby and enclosed by both evergreen and deciduous vegetation, with certain urban elements that can act as references, like the rollercoasters of the amusement park

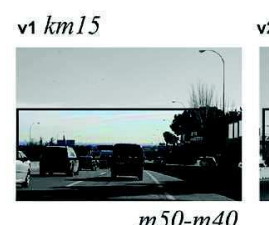

$m 50-m 40$
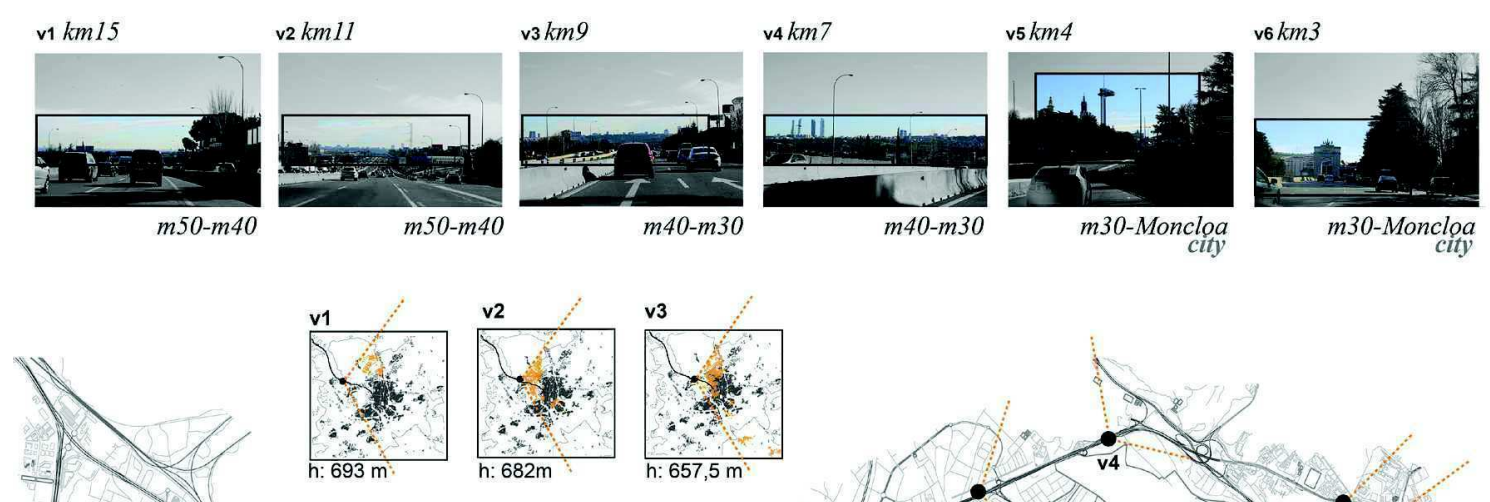

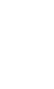

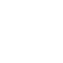


nearby. The second looks directly to some of the city's most recognizable twentiethcentury buildings that act as landmarks, with a base of evergreen vegetation and mediumsized deciduous trees. The last one shows the iconic historical view of Madrid, known as the 'cornice', composed by La Almudena Cathedral, the Royal Palace, the domes of San Francisco el Grande Basilica and other churches and old parishes, and the rooftops of the traditional domestic architecture that accompanies the historical architecture.

Main access roads as welcoming entrances:

The main access roads of the city are distributed in a radial way around the city center, and the topography enables the view of the city as a whole in certain sections along the path. There are six major highways that are the current 'arteries' of the city, and some minor roads with historical relevance. Depending on which path we take to the city, the perception varies, depicting and building on the different character types that arise along the city's periurban fringe. For instance, the experience approaching the city from the south, where the main elements are billboards and electric stations, is very different from approaching from the west, where natural landscape prevails throughout the route. Simultaneously, there are three concentric roads ( $\mathrm{m} 50, \mathrm{~m} 40$ and $\mathrm{m} 30)$ that act as proximity levels to the urban center.

For the analysis, we take the A6 road, the highway that connects Madrid with Coruña, in the northwest of Spain [Fig. 5]. It was built in 1932 as an avenue and transformed into a highway in 1968, becoming the latest of the city's six 'arteries'. A selection of the main points from where the city is perceived is made, with two predominant views per proximity level. Overall, the height of the road descends as we approach the city, with small elevation changes that condition the views.

Through the changes in the topography of said road, there are certain moments when the city, or some of its archetypal elements, are perceived. In the first two frames we appreciate the city as a whole, recognizing the skyline; at times we only appreciate a set of buildings, as in the point $\mathrm{v} 4$ where we can see the famous four towers of the north of the city; as we reach the city, individual buildings act as landmarks, like the triumphal arch of Moncloa. The landscape that surrounds the city is predominantly natural, because of the presence of some Royal Places such as El Pardo Mount (north), a Mediterranean mount filled with holm oaks, and Casa de Campo (south), a Mediterranean planted pine wood. Close to the city we find the university campus, with a landscape consisting of pines and cedar trees planted in the twentieth century. They all that act as a plinth of the city, preserving some of its iconic views.

\section{Interpretation of Results and Landscape Diagnosis}

New developments of the city can benefit from this methodology, taking the analysis as a starting point of the design process that considers multiple inputs. Landscape Characterization can be used to set the basic guidelines for environmental integration that lead to consistency in terms of ecology, landscape, territory and social activities, having an impact on the sustainability of a project, integrating sensibility and knowledge towards the site, and environmental commitment throughout the decision-making process.

As a result of the inductive approach performed, the local case studies have led to the recognition of areas of different characteristics, where certain elements stand out in the perception of the site because of their historical value, its iconic image or their predominance among other elements. By combining the results of the analysis of the lookouts and the main roads, we arrive to general conclusions regarding the understanding of the city's urban and surrounding landscape.

Linking the areas of similar attributes and taking into account the natural and anthropogenic landscape structures of the city, we begin to differentiate types in the city's peri-urban landscape. The analytical drawings of each unit take part in this identification, as they consider perceptive factors such as the relation between landmarks, barriers, relative depths between planes, sturdiness, continuity, homogeneity or representativeness. From a 

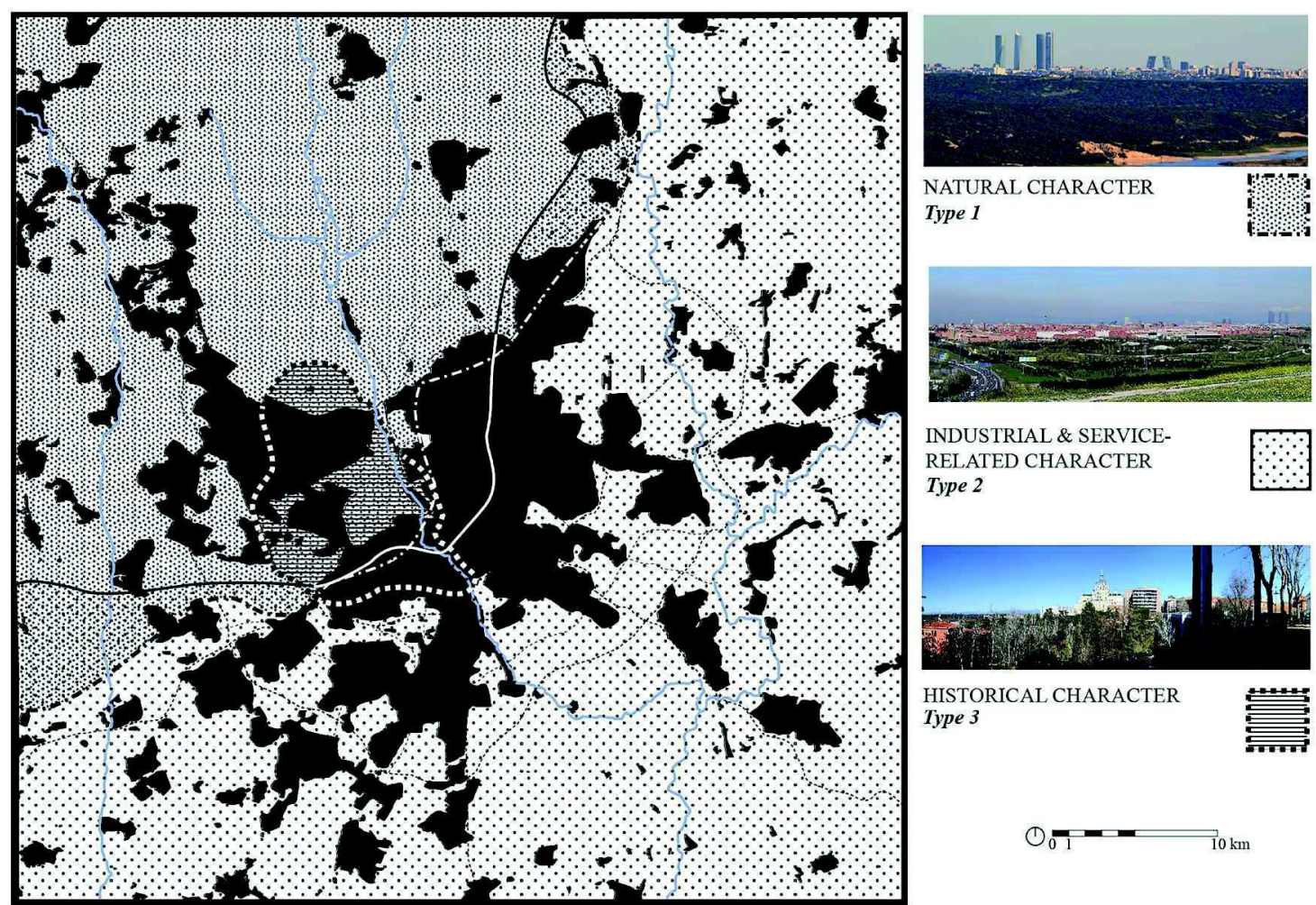

Figure 6.

Urban growth of Madrid with the different types of landscape

historical urban landscape perspective, these iconic views that remain in the collective memory are as important as the image of the historical core of the city, and are highly related to the topographical conditions. These 'proximity landscapes' become an everyday scenery for those experiencing the rural-urban fringe.

The landscape characterization accredits to distinguish three main landscape types surrounding Madrid, according to physical, natural and anthropogenic structures: one predominantly natural, one mainly industrial and service-related, and a third one with special historical relevance [Fig. 6].

-A first type opens to the north, being El Pardo Mount its main feature. Endowed with great ecological and historical value, the vegetation mainly comprises oaks, distributed alongside a Mediterranean mount. There are abundant open spaces, with few architectural elements, intertwined with the vegetation and thus usually hidden by it.

-A second type opens to the south and east. Being the largest of three described in this work, its semi-barren soil characteristics discouraged an urban expansion in that direction in the city's earliest stages. The land did not foster a strong agricultural economy either. The appearance of the railway tracks and stations in the midnineteenth century in this area gave way to a proliferation of industrial and service-related infrastructures. Despite the strong urbanization carried out later, the character given by these elements, along with an abundance of residual spaces, can still be perceived today.

-A third type opens to the west and southwest of the city centre. Its main feature is the 'cornice' of Madrid: for many centuries, the welcoming façade for those approaching the city from the west and southwest. Though still preserving its historical value, bestowed by the ensemble of protected architectural and natural structures, due to the scale of the city today, this landscape character is perceived at shorter range than in the case of the other two landscape types described above.

We appreciate a gradation throughout the northwest-southeast axis, reflected on the topography, vegetation and views alongside the Manzanares River basin. The differentiation of types is linked to the 'proximity' landscape 
scales: the first two types refer to a large scale, seeing the city as a whole, and the third type, with the river taking an active role, has an impact at a closer scale, where the iconic view of the historical city becomes the main feature.

\section{Conclusion}

Conceiving landscape as a dynamic compendium of factors calls for inclusive and multidisciplinary approaches to valorise it to its full extent. The tools and method proposed in this work could help assemble the issues involved in the study of historical urban landscape and those of current urban landscape, by not condemning historical approaches to a static and untouchable state, but rather making them part of the dynamic environment of a city in constant evolution. This can be extrapolated to other cities, especially those with similar morphological characteristics, like most European capitals. Combining the analysis of historical cartography, 3D modelling, on-site photography and analytical drawings provides a multifaceted vision of what the city means when it is contemplated.

Uncovering layers of perceptive information beyond what is visible, and considering landscape history as instrumental in decisionmaking processes, becomes especially relevant in peri-urban landscapes; areas in a temporary state of 'city-countryside border', embodying the clash between natural or rural landscape, administration boundaries and urban growth. This fringe, a 'proximity' landscape and everyday scenery for those approaching or leaving the city centre, is frequently disregarded and subject to sudden change. A deeper understanding of the landscape dynamics in these areas can guide towards a more integrated urbanism, facilitating the preservation or enhancement of certain values and places, while enabling evolution and change.

\section{Acknowledgements}

This research has been developed in the framework of the State Plan Project of the
Ministry of Economy and Competitiveness (HAR2014-57843-R), entitled "Proximity Landscapes of the City of Madrid. From the 19th Century to the present". We thank the General Secretariat of Science, Technology and Innovation for the funding of this project. Likewise, we thank the Spanish Ministry of Education for the pre-doctoral scholarship (FPU14/05524) granted to co-author Carlota Sáenz de Tejada Granados in its FPU Program. Lastly, we thank San Pablo-CEU University Foundation for the pre-doctoral scholarship granted to co-author Rocío Santo-Tomás Muro in its FPI Program.

\section{References}

Antrop, M. (2000). Background concepts for integrated landscape analysis. Agriculture, Ecosystems \& Environment, 77(1-2), 17-28. doi:http://doi.org/10.1016/S01678809(99)00089-4

Antrop, M. (2005). Why landscapes of the past are important for the future. Landscape and Urban Planning, 70(1-2), 21-34. doi:http:// doi.org/10.1016/j.landurbplan.2003.10.002

Centro Nacional de Información Geográfica (2017) National Geographic Institute, Madrid. http://www.ign.es. Accessed 16 Jan 2017

Council of Europe (2000) European Landscape Convention (COE, Florence).

Cruz, L., Español, I. (2009) El paisaje. De la percepción a la gestión (Liteam, Madrid).

Environment and Territorial Planning Department (2009) Cartografía del Paisaje. Environmental Information and Documentation Area, Madrid

Gómez Villarino, Alejandro (2012) El paisaje: Diseño de una metodología para su análisis, diagnóstico, planificación e inclusion en los procesos de toma de decisiones, doctoral thesis, Universidad Autónoma de Madrid.

Palang H, Spek T, Stenseke M (2011O Digging in the past: New conceptual models in ladscape history and their relevance in periurban landscapes, Tallinn.

Pinto, V. (coord.) (1995-2001) Madrid. Atlas Histórico de la Ciudad, Vol.1-Vol.2 (Lunwerg Editors and Fundación Caja 
Madrid, Madrid).

Planea (2017) Autonomous Community of Madrid, Madrid. http://www.madrid.org/ planea. Accessed 6 Feb 2017

Rodríguez EJ, Sáenz de Tejada C (2016) Evolution and Permanence of CityCountryside Views throughout the Urban Development of a City. Madrid as a Study Case. Procedia Engineering 161: 18791886. doi:10.1016/j.proeng.2016.08.732

Rodríguez, E.J. (2011) 'Naturaleza y ciudad: el paisaje de Madrid visto por los extranjeros', in Cabañas, M., López-Yarto, A. \& Rincón, W. (ed.), El arte y el viaje (CSIC, Madrid) 321-337.

Terán, F. (2006) En torno a Madrid. Génesis espacial de una región urbana (Autonomous Community of Madrid, Madrid).

Tudor, C. (2014) An Approach to Landscape Character Assessment (Natural England, Government of the UK).

Urban Planning and Housing Area (2009) Plan de Calidad del Paisaje Urbano de Madrid. Publicaciones Vivienda y Urbanismo, Madrid

VV. AA (1995) Madrid, Atlas histórico de la ciudad, siglos IX-XIX, Madrid.

VV. AA (2016) Madrid Regenera. Plan de regeneración urbana de Madrid. Ayuntamiento de Madrid. Susteinable Urban Planning Area

VV.AA(2010) Plan Estratégico Madrid Centro. Ayuntamiento de Madrid. Urban Planning and Housing Area.

Zárate MA (2011) Paisajes culturales urbanos, entre la protección y la destrucción. Boletín de la Asociación de Geógrafos Españoles 57:175-194 